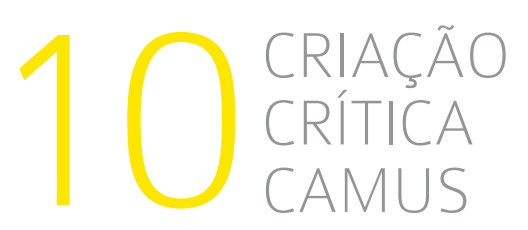

\title{
OS VÍNCULOS ENTRE O TEMA DO MAR E O LIRISMO CRÍTICO NA OBRA DE JEAN-MICHEL MAULPOIX
}

Érica Milaneze ${ }^{1}$

RESUMO: Dentre a diversidade da poesia produzida no contexto da literatura francesa contemporânea, destaca-se o lirismo crítico que tem nas obras poéticas e nos ensaios críticos de Jean-Michel Maulpoix sua formulação teórica, reflexão e expressão literária. Em alguns de seus textos poéticos, como o famoso poema "Le chant de naufragés", publicado em Dans l'interstice (1991) e as obras Histoire du bleu (1992) e L'instinct de ciel (2000), observa-se que o tema do mar atua como uma metáfora do lirismo. Desta forma, pretendemos estudar o vínculo que o tema do mar estabelece com a tentativa de caracterização do lirismo no interior destas obras poéticas do autor contemporâneo, abordando seu papel no questionamento e na criação do fazer poético do lirismo crítico.

PALAVRAS-CHAVE: poesia, lirismo, lirismo crítico, literatura francesa, poesia contemporânea, Jean-Michel Maulpoix.
ABSTRACT: Among the diversity of poetry produced in the context of contemporary French literature, highlights the critical lyricism that has the poetic works and critical essays by Jean-Michel Maulpoix his theoretic formulation, reflection and literary expression. In some of his poetic texts, as the famous poem "Le chant of naufragés" published in Dans l'interstice (1991) and works Histoire du bleu (1992) and L'instinct de ciel (2000), observed that the theme of the sea acts as a metaphor of lyricism. In this way, we intend to study the bond that establishes the theme of the sea with the attempt of characterization of the lyricism inside these poetic works of contemporary author, addressing its role in questioning and in the creation of poetry making lyricism critical.

KEYWORDS: poetry, lyricism, lyricism critic, French literature, contemporary poetry, Jean-Michel Maulpoix.

Dentre a grande diversidade de autores e estilos de escritura observados na rica produção da poesia francesa contemporânea, destaca-se o lirismo crítico, tendência poética que começa a se constituir por volta dos anos de 1980 como uma consequência da recuperação do lirismo, iniciada pelo nouveau lyrisme ou neo-lyrisme com as obras poéticas de Jacques Réda, James Sacré, Guy Goffette, Jean-Pierre Lemaire, Jean-Claude Renard, etc.. Este retorno do lirismo ao primeiro plano da cena literária, após duas décadas de predomínio das tendências neo-vanguardistas formalistas, textualistas e da chamada "modernidade negativa" - cuja vertente da pós-poesia é herdeira nos dias atuais -, voltadas para a literalidade e a experimentação, é permeado por várias publicações: os volumes especiais das revistas, Nouvelle Revue Française - cujo número 443 (1980), "Poètes des années 80", atua como um manifesto da nova tendência - e também do número 56 de Le Débat, que traz seus primeiros fundamentos teóricos, além de obras como La poésie n'est pas seule (1987), de Michel Deguy, La poésie comment dire? (1993), de James Sacré e Habiter en poète (1995), de Jean-Claude Pinson. Nos dias atuais, a produção poética de vários autores relaciona-se com o lirismo crítico, como os textos de Claude Louis-Combet, Benoît Conort, Alan Dualt e principalmente de Jean-Michel Maulpoix, considerado seu grande animador e teórico e atambém diretor da revista Le Nouveau Recueil, que agrega diversos poetas cujos ideais estéticos coincidem com essa vertente da poesia francesa do extremo contemporâneo.

É nos ensaios teóricos de Jean-Michel Maulpoix que se pode encontrar a reflexão, o questionamento e a tentativa de formulação de uma definição que dê conta da complexidade do lirismo crítico. De fato, o lirismo crítico perfaz um oximoro já a partir de seu nome, que aproxima dois elementos aparentemente inconciliáveis: o 'lírico', ligado à expressão dos sentimentos de uma subjetividade, e o 'crítico', relacionado ao questionamento racional. O lirismo crítico perfaz o gesto reflexivo inerente à própria escritura, tal qual 
elle invente, analyse et réfracte. La critique trouve refuge là où elle prend naissance: dans l'incessante relecture que fait l'écrivain de ce texte qu'il devient, dans cette surveillance où il tient ses abandons, ses impulsions ou ses impuissances. [...] Une espéce d'ultime lieu critique, tel pourrait être le poème, en ce soin qu'il continue de prendre de la langue: scène et souci, timbre et tenue, accident et contenance (MAULPOIX, 2009, p.13-4).

Consciente da impossibilidade da celebração e da efusão dos sentimentos no contexto pós-industrial, midiático e globalizado do final do século XX e início do século XXI, da mesma forma que na lírica romântica, a voz poética se volta para a alteridade e coloca em exame o próprio ímpeto lírico.

Em algumas obras de Jean-Michel Maulpoix, como o poema "Le chant des naufragés", publicando em Dans l'interstice (1991) e as obras Histoire du bleu (1992) e L'instinct de ciel (2000), o tema do mar atua, a meu ver, como uma metáfora do lirismo que permite ao poeta discutir criticamente no interior do texto a constituição e o lugar ocupado pelo lirismo no fazer poético do lirismo crítico, no contexto do final do século XX e início do século XXI.

Convém, de início, perguntar: como Maulpoix concebe o lirismo? Atrelado inseparavelmente a uma subjetividade, o lirismo se define como "une manière d'être, de parler, d'écrire" que nomeia o estado dito 'poético', no qual "le sujet est victime ou bénéficiaire d'un accès de langage"; portanto, exprime a maneira que a subjetividade do poeta "vient au poème, fait mouvement vers lui... Lyrisme, cette chaleur du discours, cette ferveur, cet emportement, ce remuement de la langue dans le corps, la voix et le souffle..." (MAULPOIX, 2000, p.23, grifo do autor). Os anseios interiores do poeta se transformam em linguagem, misturam-se a seu corpo, a sua voz e se manifestam na escritura, frutos de uma necessidade de "sortir de soi et du monde, de s'en aller à l'aventure dans le langage, de n'être plus personne, de devenir quiconque ou tout le monde, de faire chanter ses propres possibles" (MAULPOIX, 2000, p. 23, grifo nosso).

A aproximação entre o tema do mar e a construção de uma significação para o lirismo se delineiam nos ensaios do autor, em especial em Le poète perplexe (2002), que traça poeticamente algumas de suas características: "Lyrisme ... ligne de fuite, la mer prenant son large, joie de mourir ainsi à soi, de se répandre ... Là-bas, les merveilleux nuages emportent une provision de ciels. Nous voudrions mêler nos corps à cet inachevable, nos doigts, nos chevelures, et quantité d'autres fragilités désirables ..." (MaulpoIx, 2002, p. 355, grifo nosso). O mar metaforiza e materializa o ímpeto interior do poeta em expandir-se, de se tornar uma linha de fuga que se amplia e se eleva para o espaço em direção ao infinito, assim como as águas do mar se lançam a perder de vista até se confundirem com a linha do horizonte e o azul do céu. Fundir o corpo e a voz às águas do mar para fornecer uma materialidade a um desejo imaterial é uma forma de tentar atingir, mesmo que apenas por alguns instantes, o frágil infinito desejado, conforme mostram os versos do poema "Le chant des naufragés", onde a voz lírica sente o impulso de esculpir sereias de cabelos azuis com as poucas frases que lhe restam após o naufrágio de seu barco:

Nous sommes les naufragés de la langue

D'un pays l'autre nous allons, accrochés aux bois flottés de nos

phrases

Ce sont les restes d'un ancien navire depuis longtemps fracassé

Mais le désir nous point encore, tandis que nous dérivons 


\section{De sculpter dans ces planches des statuettes de sirènes aux cheveux bleus}

Et de chanter toujours avec ces poumons-là:

Laissez-nous répéter la mer

N'intentez point de procès stupide au grand lage (MAULPOIX,1991).

A aspiração ao Absoluto é, segundo Maulpoix (2000, p. 15), o princípio ativo que delineia a busca poética de uma interioridade que se vê inserida em um contexto sociocultural como uma náufraga. Com efeito, o título "Le chant des naufragés" remete ao lirismo enquanto canto, musicalidade que caracteriza a poesia lírica desde seus primórdios na Antiguidade grega, quando o aedo cantava seus versos acompanhado de um antigo instrumento de cordas, a lira, o que recupera o mito grego de Orfeu. No entanto, o lirismo visa, de acordo com a concepção de Maulpoix (2000, p. 23), à expressão de um canto sem o auxílio da musicalidade, apoiado somente na sonoridade que se depreende da linguagem contida nas profundezas interiores do poeta, ou seja, no lirismo a linguagem se faz canto. Em Histoire du bleu, o poeta ouve o som do movimentos das águas do mar em meio a seus pensamentos: " Nous écoutons monter en nous le chant inépuisable de la mer qui dans nos têtes afflue puis se retire, comme revient puis s'éloigne le curieux désir que nous avons du ciel, de l'amour, et de tout ce que nous ne pourrons jamais toucher des mains" (MAuLPoIx, 2005b, p. 31). Desta forma, o movimento das ondas do mar quebrando nas areias da praia constitui um canto que se compara ao movimento do desejo de alcançar o infinito, vontade interior que se aproxima e se afasta, aumenta e depois diminui com a consciência da impossível elevação.

É interessante notar que no poema "Le chant des naufragés" o poeta anuncia que vai exteriorizar um canto por meio de uma voz lírica; porém, este som não é a voz de um poeta, mas de um náufrago, isto é, de alguém que sofre as consequências da destruição de um navio no mar, ficando à deriva, à mercê dos movimentos e das correntes marítimas. O título fala em náufragos, não se referindo a um poeta isolado, mas aos poetas, particularmente àqueles que pertencem ao extremo contemporâneo. E é no plural que os versos se iniciam a partir de uma afirmação que será desenvolvida ao longo do texto, "nous sommes les naufragés de la langue", que agrega o pronome nous à voz que se enuncia e a todas as outras que considera semelhantes a sua e também à língua que metaforiza o barco no qual o poeta naufraga. O barco como metáfora da língua aparece ainda em L'instinct de ciel, onde o poeta questiona, "Quelle sorte de barque est la langue?", para refletir em seguida:

Pour traverser, pour s'aller, ou simplesment pour se tenir en équilibre sur le bleu. Des planches clouées, du bois taillé: il faut un arbre ou plusieurs pour aller sur la mer. [...] Il faut avoir aimé les souffles de la langue, ses feuillages et ses chants. [...] Il faut avoir un peu de terre sous les semelles pour marcher sur la mer. (MAULPOIX, 2005b, p.160)

Barco feito de madeira, a língua se origina no tronco das árvores, na própria natureza e, portanto, reenvia à linguagem primordial. Ao fundir-se com a língua, o poeta recobra a antiga união entre o homem e natureza, escrevendo seus versos com a própria linguagem original. Estabelece-se uma ligação entre o poeta e a linguagem que está na essência do lirismo, uma vez que a voz poética enuncia e constrói um mundo por meio da linguagem em sua escritura: a relação entre poeta e linguagem "donne le monde à voir, à goûter, peut-être 
à posséder, sur un mode tel que la réalité est perdue de vue en même temps qu'idéalement et singulièrement rejointe" (MAULPOIX, 2000, p. 16). Em Histoire du bleu, o lirismo materializado pelo som das águas do mar se torna uma fala interior que dita e murmura frases ao poeta, desde sua infância:

La mer en nous essaie des phrases.

Depuis des lustres, la même voix épelle le même alphabet dans le même cerveau d'enfant. Elle balbutie des mots vite envolés, accrochés aux herbes des plages, à la peau brunie des baigneurs, à la proue des barques, aux mâtures. Des mots quelconques, pour rien et pour quiconque. (MAuLPoIx, 2005b, p. 32)

Tais palavras nascem em comunhão com os outros elementos que se ligam à rede semântica do mar, às ervas da praia, à pele dos banhistas, à proa dos barcos, que quando unidos pelos fios do lirismo constituem o texto poético. Por meio da imaginação, a linguagem lírica concretizada na escritura pela metáfora do mar possibilita a união do 'eu' poético com a natureza exterior, sendo que a realidade perde suas referências para reorganizar-se de acordo com as diretrizes do ímpeto lírico em uma realidade essencial. Assim, a imaginação e o desejo reúnem o mar com as algas, os alcatrazes e outros elementos que compõem os sonhos do poeta aos crisântemos, aos miosótis, aos faróis situados na beira da praia, na terceira estrofe do poema "Le chant des naufragés", a fim de colocar em discussão no interior do texto poético a analogia entre o homem e a natureza, perfazendo a busca poética que compreende a reflexão crítica do ato de escritura do lirismo:

La mer se mêle avec la mer

Mélange ses lacs et ses flaques

Ses idées de mouettes et d'écumes

Ses rêves d'algues et de cormorans

Aux lourds chrysanthèmes bleus du large

Aux myosotis en touffes sur les murs blancs des îles

Aux ecchymoses de l'horizon, aux phares éteints

Aux songes du ciel impénétrable (MAuLPoIX, 1991).

A linguagem é, então, como denota a estrofe, a responsável pela união do ser com o mundo exterior, recorrendo para tanto a um encadeamento de metáforas, em que a metáfora do mar se expande e se dobra em outras metáforas, ou melhor, a voz e a expressão do poeta efetuam um desdobrar da linguagem sobre si mesma, movimento que traduz a expressão do lirismo no poema: "[...] le lyrisme va vers le langage dans le langage. Le chant lyrique est ce mouvement, ce renchérissement de la parole sur elle-même, qui est aussi bien le redoublement des choses dans leurs reflets, leurs métaphores, ou la répétition de l'être en soi-même" (MAulPoix, 2000, p. 17). O autor explica no ensaio Du Lyrisme, que ao expor uma postura lírica, a linguagem deixa de se organizar de forma ordenada e racional para articular-se em uma voz e conquistar uma pluralidade de sentidos, em que o ser e a língua revelam seu recíproco pertencimento (MAuLPOIX, 2000, p. 16).

Retomando a primeira estrofe de "Le chant des naufragés", no segundo verso, "d'un pays l'autre nous allons, accrochés aux bois flottés de nos phrases", se constata que o poeta/náufrago permanece à deriva no 
mar, agarrado aos restos do navio que correspondem aos fragmentos de suas frases que sem rumo definido, perdidos no mar da linguagem, não conseguem se rearranjar no conjunto do texto poético; por isso, o poeta viaja por meio de sua imaginação de um país a outro, à semelhança do estrangeiro, homem de passagem e sem laços que reenvia ao poema em prosa baudelairiano "L'étranger", publicado em Les petits poèmes en prose, analisado por Maulpoix:

Qui aimes-tu le mieux, homme énigmatique, dis? ton père, ta mère, ta soeur ou ton frère ? [...]

- La beauté? - Je l'aimerais volontiers, déesse et immortelle.

[...] - Eh! qu'aimes-tu donc, extraordinaire étranger?

- J'aimes les nuages ... les nuages qui passent ... là-bas ... les merveilleux nuages! (BAUdelaIRE, 1998, p. 27).

Segundo a releitura do autor contemporâneo, o estrangeiro é o homem que ama a beleza fugaz, o eterno transitório inatingível, um amor "dans le présent, de ce qui s'en échappe, amour d'une aspiration indéfinie, merveilleuse en ce qu'elle allège, élève, et dégage des 'miasmes morbides' pour emporter dans les espaces limpides" (MAulpoix, 1998, p. 71, grifo nosso). Ao apropriar-se da metáfora baudelairiana que assimila o poeta ao estrangeiro, Maulpoix traz para seu discurso o deslocamento que o poeta se submete por estar inserido em um contexto particular, que situa tanto o poeta moderno como o contemporâneo como seres em trânsito sobre a terra, como comenta no item "Le poète marche sur la terre", do texto "Le danseur de corde", que compõe o ensaio Le poète perplexe:

Sur cette terre est sa vie, son paysage, son séjour et son horizon. Là est son transitoire, là se rencontrent ses semblables. Passant, passeur et passager, il s'y trouve en transit, coincé entre une naissance et une disparition dont il ne décide pas, n’ayant guère la maîtrise que de ses allées et venues. [ ...] En chemin dans la vie comme dans la langue, il interroge une provenance et une destination. Il répète « aller me suffit ». [...] (MAULpoIx, 2002, p.19, grifo nosso)

Estrangeiro, o poeta é um viajante que percorre um mundo inteiro com seus sonhos e sua imaginação, realizando uma verdadeira viagem por meio da escritura. Resta ao poeta contemporâneo permanecer à beira da praia ou perambular pelas ruas da cidade para recolher os elementos e as percepções exteriores que podem ajudar na criação de seus versos. O lirismo e o poeta estão encalhados na terra e, como tal, podem apenas rememorar as viagens do passado. Em L'instinct de ciel, o barco está ancorado na praia enquanto o poeta se dedica a outras atividades, embora ainda guarde dentro de si as lembranças de suas aventuras no mar:

La barque est à sec sur la grève. Cet homme à nouveau marche au bord du bleu où il ne s'en va plus. Ce n'est plus le soleil du large, mais le temps qui creuse son visage. Il a remisé ses filets: il n'y prendra plus de poisson d'or, encore moins de sirènes. II nettoie ses outils: pelle et pioche au petit jardin. Il travaille à présent entre des murets de pierres sèches. II rentre quand il fait grand vent. Son dos se voûte, son pas est lourd. De la mer, il lui reste la pensée, et de lointains une espèce de blessure dans le regard, un tremblement léger des mains, une façon d'absence ou de distraction quand autour de 
lui on s'agit. Jamais vraiment là, en fin de compte, même s'il a repris pied sur le sol, comme si cette histoire n'était pas tout à fait la sienne. (MAULPoIX, 2005b, p. 159)

Neste sentido, o autor discute no seio de seus textos poéticos a impossibilidade da criação de um lirismo da celebração e do pathos idealizante, tal qual na lírica romântica, como forma de satisfazer sua busca pelo Infinito no contexto sociocultural dos dias atuais, em que se diz "adieux au poème", forma estética que tradicionalmente se organiza como "tissage de figures, objet de beauté, densité de faits de langue, respiration accélérée ou très lente de la pensée. Évidence et perplexité. [...] Le poème, tel que nous l'avons aimé, [...], est un objet perdu" (Maulpoix, 2005a, p. 16). Para dizer adeus à forma tradicional do poema, Maulpoix publica um extenso ensaio - Adieux au poème (2005) - , porque acredita que o poema está em vias de esquecimento, devido ao fato de seus contemporâneos renunciarem à busca pelo Absoluto por meio das palavras: "[...] dans la marchandise, ils trouvent dans la stupéfaction leur content. Bousculés dans le tohu-bohu des villes, roulés dans la farine des images, ayant jeté l'éponge, ils ne cherchent plus guère à reprendre pied sur la terre dont ils se sont eux-mêmes exclus" (MAuLPoIx, 2005a, p.16).

Em vista disto, algumas obras de Maulpoix apresentam o mar em seu aspecto decrescente durante a maré baixa, em consonância com a voz e a disposição dos sentimentos melancólicos do poeta, que passa a refletir acerca do lugar e do papel da escritura poética dentro do contexto de sua época, ao mesmo tempo que aponta a ilusão em que se transformou seu desejo de atingir o Ideal e a Beleza como forma de expressar a realidade plena em seus versos. Desta forma, em uma das tentativas de definir o lirismo crítico, Maulpoix (2002, p.357, grifo nosso) afirma com uma linguagem poética: "Aujourd'hui, c'est marée basse! Ni chants de sirènes, ni tempêtes sublimes: nous ne recueillons sur la plage lessivée que les embruns salés des vagues et ce butin maigre de bois flottés, de coquilles et de morceaux de verre que le profond silence des mers parcimonie nous octroie". Preso à terra, o poeta consegue recolher nas areias da praia, varridas e reviradas pelas ondas do mar após a ressaca, os fragmentos de suas frases, transformados em restos de algas, pedaços de garrafas de vidro, de madeiras e de conchas. Nos dias atuais, cabe ao poeta apenas contemplar o mar da praia, das pedras dos diques e dos portos, sonhando com uma possível viagem por meio de uma escritura que baixa o tom e expressa uma certa melancolia:

\section{L'un d'entre nous parfois se tient debout près de la mer.}

Il demeure là longtemps, fixant le bleu, immobile et raide comme dans une église, ne sachant rien de ce qui pèse sur ses épaules et le retient, si frêle, médusé par le large. Il se souvient peut-être de ce qui n’a jamais eu lieu. II traverse à la nage sa propre vie. II palpe ses contours. II explore ses lointains. Il se laisse en lui se déplier la mer [...] (MAuLPoIx, 2005b, p. 33, grifo nosso)

Como resultado, o mar acaba por se assimilar ao céu como mostra a metáfora presente na sexta estrofe do poema "Le chant des naufragés », onde o céu azul é caracterizado pelo adjetivo 'caído': é como se o céu despencasse das alturas e se unisse ao mar para formar, por assim dizer, um Absoluto baixo que se expande horizontalmente sobre a terra: 


\section{La mer est un ciel bleu tombé}

Voici longtemps déjà que le ciel a perdu ses clefs dans la mer

Sous quels soleils désormais nous perdre?

Sur quelle épaule poser la fièvre de notre tête humide?

Nos rêves sont des pattes d'oiseaux sur le sable

Des fragments d'ongles coupés à deux pas de la mer

Nous brûlons sur la plage des monceaux de cadavres

Puisque tels sont les mots avec leurs os et leurs fumées (MauLpoix, 1991, grifo nosso)

A partir daí, o poeta questiona acerca da postura que deve adotar, uma vez que não se coloca mais em jogo a necessidade de elevação aos cimos dos céus. Dispersos pela praia, os fragmentos dos sonhos de elevação são transformados pela analogia nos restos de uma ave despedaçada que é queimada nas areias e que correspondem aos pedaços das frases que se destacam do poema após o naufrágio do barco/língua. Advém, então, o questionamento crítico do poeta, "Pourquoi ne pouvons-nous prendre racine dans la mer / À la façon des noyés et des algues ?" (MauLPoıx, 1991), cuja resposta incide na hipotética criação de uma união definitiva com o infinito e, por conseguinte, no término de seus lamentos com a constituição de um novo discurso poético:

Nous porterions sans peine sur nos épaules
Le ciel bleu qui ne se fane pas mais rêve à des couleurs
Et la laine tiède des écumes
Et les fruits vénéreux du large
Où n'a mordu nulle lèvre humaine
Nous serions de retour dans l'infini jardin
Nous ne remplirons pas la mer nos larmes
Nos soutiendrons plutôt de nos chants l'effort des tempêtes
Qui versent sur nos têtes cris et leurs lessives
Et quand nos yeux délavés n'y verront plus rien
Nous saurons mieux encore ce qu'est la mer
Les écailles seront tombées qui nous couvrent le coeur
Et notre peau nacreuse sera enfin si blanche
Que nous ne craindrons plus l'amour fou des sirènes
(Maulpoix, 1991)

Enfim, o tema do mar atua nos textos analisados de Jean-Michel Maulpoix como uma metáfora do lirismo, que auxilia na tentativa de constituição de uma definição do lirismo no interior do texto poético, simultaneamente ao questionamento da impossibilidade de criação de um lirismo da exaltação e do pathos no contexto atual. Tais questionamentos inseridos na escritura poética acabam por colocar o poeta em uma postura crítica, determinando um discurso a um só tempo lírico e crítico. 


\section{REFERÊNCIAS}

Baudelaire, C. Petits poèmes en prose (Spleen de Paris). Paris: Pocket, 1998.

Degur, Michel. La poésie n'est pas seule. Court traité de poétique. Paris: Seuil, 1987.

LE DÉBAT, Paris, n. 54, mars-avril 1989.

Maulpoix, J. M. Adieu au poème. José Corti, 2005a.

. Du lyrisme. Paris: José Corti, 2000.

. Histoire du bleu suivi de L'instinct de ciel. Paris: Gallimard, 2005b.

La poésie comme l'amour. Paris: Mercure de France, 1998.

"Le chant des naufragés". In: Dans l'interstice. Paris: Fata Morgana, 1991. Disponível

em: http://www.maulpoix.net/naufrages.htm . Acesso: 28/12/2010.

. Le poète perplexe. Paris: José Corti, 2002.

. Pour un lyrisme critique. Paris: José Corti, 2009.

Nouvelle Revue Française: Poètes des années 80, Paris, n. 443, déc. 1980.

Pinson, J. C. Habiter en poète. Seyssel: Champs Vallon, 1995.

SACRÉ, J. La poésie comment dire? Paris: André Dimanche, 1993.

ARTIGO RECEBIDO EM: 02 jan. 2013.

ARTIGO ACEITO EM: 20 abr. 2013.

REFERÊNCIA ELETRÔNICA: MILANEZE, Érica. Os vínculos entre o tema do mar e o lirismo crítico na obra de Jean-Michel Maulpoix. Revista Criação \& Crítica, n. 10, p. 73-80, maio 2013. Disponível em: 〈http://www.revistas.usp.br/criacaoecritica〉. Acesso em dd mmm aaaa. 